of the gall bladder. One other short-term typhoid carrier and two long-standing carriers of other Salmonella species were cleared. Further observations are needed both of the treatment of established carriers and particularly of the frequency of the carrier state after treatment of the disease itself. It is reasonable to hope that in view of the bactericidal action of this combination the organism may at least more often be actually eliminated. The studies of Kamat and others reported here should certainly serve to encourage others toadopt this treatment and form their own opinions.

\section{Alcoholism Neglected}

Difficulties in defining alcoholism have resulted in widely varying estimates of its prevalence. $A$ recent one ${ }^{1}$ is that there are between 200,000 and 400,000 alcoholics in England and Wales. If correct this means that about $1 \%$ of the adult population is afflicted. The number of alcoholic patients treated in hospital in England and Wales in 1967 was over 7,500 - a rise of nearly tenfold in fifteen years.

Not all alcoholics need inpatient care, but in the United States it is suggested that about $25 \%$ of alcoholics have physical or psychological complications. ${ }^{1}$ Even if this figure was halved and applied to England and Wales, where alcoholism is less widespread than in the United States, then between 20,000 and 50,000 patients would seem to need treatment. If these patients materialized in the surgeries and the hospitals the already heavy load on the health services would be increased. The fact that they have not suggests that most alcoholics are not seen by doctors or, if so, not diagnosed.

Alcoholism may be distinguished from excessive social drinking and cannot be used to describe the individual who has occasional bouts of drunkenness. In $1960 \mathrm{Keller}^{2}$ produced a short definition, describing it as "a chronic disease manifested by repetitive implicative (suspicion arousing) drinking so as to cause injury to the drinker's health or to his social or economic functioning."

It was to educate the public and doctors about this largely hidden disease and to co-ordinate the medical profession's attack on it that the Medical Council on Alcoholism was founded three years ago. Started informally by a group of doctors with experience of treating alcoholism, it has since attracted financial support from an anonymous private foundation. This has allowed the council, now under the presidency of Sir Max Rosenheim, to sponsor some research projects which range from studies of the biochemistry of alcoholism to a survey on attitudes to drinking. At a press conference last week the council gave a preliminary progress report on these projects, reiterated some of the facts known already about alcoholism, and indicated its intention to widen the field of knowledge as funds become available. ${ }^{3}$ Estimating the possible cost to industry as $£ 100$ million a year, and noting that the Government received the sum of $£ 1,500$ million annually from the liquor industry the council suggested that money might be provided from these two sources towards exploring methods of prevention and treatment. This proposal has the attractiveness of simplicity and justice.

However, there are some massive obstacles to be overcome

1 Alcohol Abuse. London, Office of Health Economics, 1970.

Keller, M., Quarterly fournal of Studies in Alcohol, 1960, 21, 125. Report on Alcoholism. London, The Medical Council on Alcoholism
Limited, 1970. in tackling alcoholism. It is still regarded by the public and even by doctors as a social stigma rather than as a disease. Far from seeking treatment afflicted persons and their families will go to extraordinary lengths to disguise their "weakness." This makes recognizing alcoholism particularly difficult for busy doctors, who may easily overlook excessive alcohol intake as a contributory factor to a patient's illness. Firms may dismiss sufferers-many of whom are in middle age-in a way they would not dream of doing to victims of other more acceptable diseases. Such attitudes make rehabilitation, already notoriously difficult for alcohol addicts, even more difficult.

The council is probably right when it says that medical students and doctors are not taught about alcoholism. Not so long ago all clinical students were regularly admonished by their teachers not to forget the spirochaete when assessing the differential diagnoses of a patient. Perhaps the same should now be said of alcohol for, like syphilis, it can present in an extraordinarily wide age range and in a variety of ways, and its abuse is on the increase. ${ }^{3}$

So far there are fewer than a score of special treatment centres in Great Britain and with Health Service resources overstretched the prospect for starting more seems remote. Perhaps, as the Medical Council on Alcoholism proposes, the distilling industry and the Government could be persuaded to direct some of the money they receive from alcohol sales towards the prevention and treatment of its misuse. There is already an N.H.S. precedent, though on a tiny scale, in that drivers through their motor insurance companies contribute towards the treatment of road accident injuries. Would it be too much to hope for a demonstration of imagination and flexibility from the Government, with the setting up of a pilot experiment along these lines in say Scotland, where the problem is even more intractable than in England and Wales?

\section{Cancer Hazards in the Laboratory}

The publication and wide circulation of a code of practice ${ }^{1}$ for laboratory workers who handle carcinogenic aromatic amines has drawn attention to the need for extreme care in handling specified agents. They include $\alpha$ - and $\beta$-napthylamine, benzidine, 4-aminodiphenyl, orthodianisidine, 4-nitrodiphenyl, orthotolidine, or the salts of these compounds. These substances are known to cause or suspected of causing bladder cancer in workers engaged in their manufacture or handling them on a large scale. The incidence of bladder cancer among laboratory workers, some of whom have been exposed intermittently to carcinogenic aromatic amines, has not been the subject of an epidemiological survey. Nevertheless, an increasing number of individual case reports leaves

\footnotetext{
1 Chester Beatty Research Institute, Precautions for Laboratory Workers who Handle Carcinogenic Aromatic Amines. Code of Practice Drawn up by the Harlow Industrial Health Service and the Chester Bcatty Research the Harlow Industrial Health Service and the Chester Bcatty Resear
Institute, p. 1, London, Chester Beatty Research Institute, 1966.

2 Li, F. P., Fraumeni, J. F., jun., Mantel, N., and Miller, R. W., fournal of the National Cancer Institute, 1969, 43, 1159.

World Health Organization, Manual of the International Statistical Classification of Diseases, Injuries and Causes of Death, seventh revision; vol. 1, p. 1. Geneva, World Health Organization, 1957.

- United States, National Vital Statistics Division: Special Reports, 1963, 53, No.5 p. 452.

5 Miller, J. F. A. P., Advances in Cancer Research, 1961, 6, 291.

- Doak, P. B., Montgomerie, J. Z., North, J. D. K., and Smith, F., British Medical Yournal, 1968, 4, 746.

Fraumeni, J. F., and Miller, R. W., fournal of the National Cancer Institute, $1967,38,593$.

- Darlow, H. M., Simmons, D. J. C., and Roe, F. J. C., Archives of Environmental Health, 1969, 18, 883.
} 
little room to doubt that the risk of developing bladder cancer is increased by exposure to certain aromatic amines in the laboratory. The careless use of benzidine in testing for occult blood and in spraying chromatographs are particular examples of where hazards may occur.

Studies on laboratory animals point to many other agents used in laboratories as possibly being carcinogenic in man, but it is difficult to pinpoint which of the suspect compounds are really hazardous. A chemical agent that gives rise to cancer of one type in one animal species may predispose to cancers of one or more entirely different types in another. Laboratory workers may handle a multitude of chemical compounds during the course of a working life-time, and a long and variable latent interval between start of exposure to a carcinogen and the first evidence of its effect renders the task of associating cause with effect difficult. The fact that exposure may cease long before cancer develops serves to magnify the difficulty further. In any case cancer of one type or another is such a common disease that when it occurs in a laboratory worker the possibility of its being occupational in origin is easy to overlook.

A report from the Epidemiology Branch of the National Cancer Institute in Bethesda ${ }^{2}$ should increase general awareness of carcinogenic hazards in laboratories. F. P. Li and his colleagues scrutinized 3,637 out of a possible 4,644 death certificates relating to members of the American Chemical Society who died between April 1948 and July 1967 and coded the causes of death according to the World Health Organization manual. ${ }^{3}$ They then compared frequencies of death from specific causes with expected frequencies based on the mortality of professional men in comparable age groups. 4 Among male chemists of 20-64 years of age there were 444 deaths from cancer against 354 expected. Of the 90 excess cancer deaths 41 were attributable either to malignant lymphoma or to cancer of the pancreas. Cancer of one form or another was also commoner than expected as a cause of death in male chemists over the age of 64 (250 compared with 218). In this case, cancer of the pancreas or lymphoma accounted for 23 of the 42 excess deaths and cancers of the intestines or rectum for 12. Deaths from cancers of the lung and stomach, on the other hand, were less frequent in chemists than expected. $\mathrm{Li}$ and his colleagues did not find a significant excess of deaths from cancer of the urinary bladder, but the numbers of cases expected and found were small.

The authors list several reasons why their findings should be interpreted with caution. However, the consistency of the findings makes it unlikely that the excessive risks of death from lymphoma and pancreatic cancer are attributable to chance. An important aspect of the findings is that they provide a clue to the causation of cancer of the pancreas in man.

Many agents are known to increase the risk of lymphoma development in various species of laboratory and domestic animals. Several of them probably act indirectly by changing the immunological or hormonal status of animals or by interfering with some virus-host relationship in another way. There may well exist a similar variety of possible ways of increasing the risk to man of developing lymphoma. ${ }^{5-7}$

The results of further epidemiological studies and of detailed investigations of the occupational histories of individual chemists who develop cancer will be awaited with interest. In the meantime, greater awareness of cancer hazards is certainly needed in laboratories. It will be stimulated and guided by the publication of recommended codes of practice that refer to all known classes of chemical carcinogen. A proposal $^{8}$ to appoint safety officers, similar to radiation protection officers, with authority to see that chemical carcinogens are not used without adequate precautions deserves serious consideration.

\section{Headache and Hypertension}

For years doctors have disputed the association between headache and hypertension, but the public do not share the same doubts. They know that high blood pressure causes headache and that headache is an indication for a blood pressure check. Patients see an obvious cause-and-effect relationship between high pressure in the blood vessels and pain in the head. Many physicians agree. ${ }^{1}$ The typical hypertension headache is usually said to be throbbing in character and worst on waking in the morning, ${ }^{2}$ but headaches in hypertensive patients may have other explanations than the high blood pressure. Neurosis seems to be common among hypertensive patients. ${ }^{3}$ Neurotic people visit their doctors more often than non-neurotic people, and so their symptomless hypertension is more likely to be discovered. ${ }^{4}$ Headache may develop as a neurotic symptom after hypertension is discovered. ${ }^{5}$ Few doctors would seriously regard high blood pressure as a result of psychic rather than renal disorder, but it has even been suggested that neurosis may be the cause of both the headache and the hypertension. ${ }^{6}$

Headache is a common affliction, and its apparent association with high blood pressure may be owed to its often being reported when patients are examined for hypertension. The relevance of the hypertension to the headache thus remains surprisingly blurred, and the report of a recent study carried out in Glasgow is welcome. ${ }^{7}$ In this study R. H. Al Badran and colleagues compared the incidence and type of headache in a group of hypertensive patients with those in a control group of normotensive patients. The study showed a steadily increasing incidence of headache in patients with diastolic pressures of $125 \mathrm{~mm}$. Hg or more, but there was no greater incidence of headache in patients with mild or moderate hypertension than in the control group. The headache in the severe hypertensives tended to recur daily on waking, it was shortlived, and it was poorly localized. Good control of blood pressure relieved the headache in most of these patients, but poor control did not usually do so.

By contrast with the severe hypertensives the milder hypertensives suffered headaches similar in incidence and character to those among the matched controls. They were often occipital and of longer duration but less frequent than in the severe hypertensives. In the normotensive controls and in patients with hypertension who failed to gain relief of headache despite good reduction of blood pressure cervical spondylosis was a commoner radiological finding than it was in the patients without headache or in those whose headache had been relieved by therapy.

1 Wolff, H. G., Headache, 2nd edn. London, Oxford University Press, 1963. 2 Platt, R., British Medical fournal, 1950, 1, 951.

3 Pickering, G., High Blood Pressure, 2nd edn., p. 324. London, Churchill, 1968 .

4 Robinson, J. O., Wood, M. M., British Fournal of Preventive and Social Medicine, 1968, 22, 23.

Stewart, I. McD. G., Lancet, 1953, 1, 1261.

- Al Badran, R. H., Weir, R. J., and McGuiness, J. B., Scottish Medical fournal, 1970, 15, 48 .

${ }^{8}$ Pickering, G. W., Clinical Science, 1934, 1, 397. 